\title{
Experiências pessoais e suas implicações nas práticas de ensino
}

\author{
Personal experiences and their implications for teaching practices
}

\author{
Rejane Silva Penna* \\ Gilberto Ferreira da Silva**
}

RESUMO

O texto apresenta uma análise das histórias de vida de professores e suas traduções na prática docente. Situa, inicialmente, o cenário das pesquisas que utilizam fontes orais como recurso de investigação aplicado ao campo da educação e explora o potencial das entrevistas como método de coleta de informações, argüindo sobre a importância e a complexidade do uso desse tipo de fonte para a pesquisa em educação. Finalmente, expressa a reflexão, sustentada em duas trajetórias de educadores, em que se destacam aspectos como a tradução da experiência pessoal nas suas escolhas e práticas docentes, tanto no ensino superior quanto na educação básica.

PALAVRAS-CHAVE: Memórias de professores; metodologia de pesquisa; fontes orais; práticas docentes; formação de professores.
ABSTRACT

The article brings an analysis of the life stories of teachers and their implications in their teaching practices. First of all, present the scenario of researches that make use of oral sources as resource for their investigations applied to the field of education and explore the potential of the interviews as a method for collecting data, always arguing about the importance and complexity of the use of this kind of source in researches in education. The conclusion expresses a reflection, based on the teaching career of two educators, which highlights aspects related to the implication of the personal experience in their teaching options and practices, covering both higher education and elementary/high school levels.

KEYWORDS: Teachers' memories; research methodology; oral sources; teaching practices; teachers' education.

\section{Introdução}

Nos últimos anos, as pesquisas sobre formação docente têm destacado a importância de analisar a prática pedagógica tendo o professor como foco central e considerando o quanto o "modo de vida" pessoal acaba por interferir no profissional (NUNES, 2001). Esse caminho abre perspectivas que possibilitam evidenciar a importância de pensar a formação de professores para além do acadêmico, envolvendo o desenvolvimento pessoal, profissional e

\footnotetext{
Doutora em História pela Pontifícia Universidade Católica do Rio Grande do Sul (PUC-RS) e Historiógrafa do Arquivo Histórico do Estado do Rio Grande do Sul (AHRS) / Brasil.

** Doutor em Educação pela Universidade Federal do Rio Grande do Sul (UFRGS) / Brasil e Pós-doutorando na Universitát de Barcelona (UB) / Espanha. Professor do Centro Universitário La Salle (UNILASALLE) / Brasil.
} 
organizacional do docente em uma abordagem téorico-metodológica que valoriza a narrativa como chave compreensiva da tradução das experiências pessoais para o ensino.

Alguns trabalhos já incursionaram por essa área, concluindo que tanto as experiências vivenciadas no processo de escolarização, quanto as experiências acadêmicas e profissionais contribuem para a forma como se configura o exercício docente (PINTO, 2001; NUNES, 2001). Entretanto é insuficiente o número de pesquisas que refletem sobre os elementos constitutivos da prática docente no que se refere contribuição da história de vida na visão de educação dos professores e o quanto permanece como norteadora na prática pedagógica.

O presente trabalho insere-se nessa paisagem, buscando, a partir dos apontamentos introdutórios, explorar os efeitos das trajetórias de vida de educadores em suas práticas docentes. Como podem ser percebidos os traços das vivências pessoais nas narrativas de docentes sobre sua prática profissional? Levando em consideração o caráter dinâmico e seletivo da memória, como reconstroem suas reminiscências e evidenciam aspectos que permitem alicerçar uma crítica sociedade e ao mundo do ensino?

Buscando um esclarecimento a essas problemáticas, foram utilizadas duas entrevistas realizadas no ano de 2006. ${ }^{1}$ Trabalhou-se com um roteiro de questões preliminares, com o objetivo de orientar o entrevistador; sendo que o pólo mobilizador foi a busca por evidências, através da memória da trajetória escolar, para perscrutar como ocorrem essas relações entre experiência de vida e prática profissional.

oportuno destacar, a respeito do reduzido número de entrevistas utilizado, que muitos autores levam em consideração o que se denomina "ponto de saturação", admitindo que a coleta de depoimentos ocorra até alcançar o nível de repetição do já dito. Através da saturação, poder-se-ia generalizar um grupo de relatos, o que, em última instância, validaria a investigação. Mas não faz sentido reivindicar a validez da metodologia pela quantidade de relatos que permitiriam chegar ao "ponto de saturação", pois uma única história de vida é representativa o suficiente, dependendo do objeto da pesquisa em questão.

\footnotetext{
1 As entrevistas analisadas neste trabalho foram realizadas pelas alunas Ana Regina Alves Garcia, Andréia Grala Mendonça e Teresinha Carmelita Marchry, sob orientação do professor Gilberto Ferreira da Silva, durante a disciplina Pesquisa e Investigação na Docência (2006/2) do curso de Pedagogia.
} 
$\mathrm{Na}$ realidade, discutir o número ideal de entrevistados parte de uma perspectiva neopositivista de ciência, que ainda exige uma "verdade científica", de certa forma, mensurável, estranhamente inserida em uma análise qualitativa, em tese, questionadora da descoberta de regularidades e constâncias para afirmar a representatividade de algo. Amparamo-nos, para pensar essa questão, no raciocínio de Grisa (1999), o qual questiona a própria noção de validez, que se modifica quando a opção epistemológica sofre uma mudança, pois, dependendo do paradigma adotado, o número de relatos coincidentes é irrelevante.

Nesse sentido, Rousso (1996) ressalta o caráter social e coletivo da memória, como elemento predominante, não aceitando sua individualização pura e simples:

A memória, para prolongar essa definição lapidar, é uma reconstrução psíquica e intelectual que acarreta de fato uma representação seletiva do passado, um passado que nunca é aquele do indivíduo somente, mas de um indivíduo inserido num contexto familiar e social e nacional (p.96).

Ou seja, histórias de vida não são úteis para reconstruir fatos ou pessoas tais como foram ou são, mas, para termos acesso a arquivos de valores e sistemas de pensamentos.

\section{Formação pessoal e profissional: cacos para compor mosaicos de vida}

A proliferação de pesquisas que integram as fontes orais como metodologia na área da Educação pode ser comprovada pela revisão bibliográfica realizada por um grupo de pesquisadoras da Faculdade de Educação da Universidade de São Paulo, contemplando o período de 1985 a 2003, a partir, principalmente, de informações contidas no banco de teses da Capes, demonstrando a polissemia de termos, enfoques e abordagens teóricas no tratamento dado ao uso da metodologia de fontes orais. Segundo as autoras:

\footnotetext{
As histórias de vida e os estudos autobiográficos como metodologias de investigação cientifica na área da Educação ganharam visível impulso no Brasil nos últimos quinze anos. Em comparação com o período anterior, a década de 1990 traz grandes mudanças, apresentando um crescimento vertiginoso dos estudos que fazem uso dessas metodologias, genericamente denominadas de autobiográficas (BUENO et . all, 2006: 387).
}

Mesmo considerando a trajetória histórica do uso dessa metodologia no campo da educação, inicialmente com forte contribuição dos pesquisadores 
norte-americanos e europeus, e suas repercussões no território acadêmico brasileiro, servindo como estimuladores e propiciadores da abertura para o seu uso, constata-se que os efeitos dessas produções acabam limitando-se a este start, não havendo grande ressonância das concepções defendidas por esses pesquisadores nos trabalhos produzidos nos estudos mais contemporâneos de seus pares brasileiros (BUENO et. all, 2006: 393).

Por outro lado, enfatizam as pesquisadoras, em suas considerações finais, que o uso dessa metodologia propiciou um florescimento de interesse por questões inovadoras no campo da formação de professores. Dentre os temas destacados situam-se os da profissão e da identidade docente. Chamam a atenção, igualmente, para o fato de que as produções realizadas no contexto brasileiro pouco dialogam com outras pesquisas, como é o caso da produção gerada a partir dos países latino-americanos, considerando que são nações que apresentam uma maior similaridade das problemáticas no campo da educação, assim como no que diz respeito aos aspectos culturais, econmicos e sociais, se comparadas aos estudos realizados por pesquisadores nos contextos europeu e norte-americano.

Surge, então, uma outra problemática nesse campo investigativo: o uso da própria metodologia e seu potencial para contribuir na elucidação das relações que se constituem entre os diversos e diferentes campos que envolvem a formação de professores. Destaca-se, em especial, um deles: as possíveis relações que se pode estabelecer entre as trajetórias de vida dos professores e sua atuação docente.

Com relação ao primeiro aspecto, Nóvoa, refletindo sobre o potencial da metodologia de histórias de vida no campo da formação de professores, propõe dois pontos de vista. O primeiro, denominado pelo autor como prático, é onde "verifica-se a ausência de uma teoria da formação dos adultos, que forneça um suporte sólido elaboração de modelos inovadores e realização de práticas alternativas" (2000: 19); o outro, identificado como teórico, parte do pressuposto de que "as fragilidades conceptuais das Ciências da Educação provocam uma necessidade de afirmação com base nos paradigmas científicos dominantes, o que dificulta a emergência de novas perspectivas” (idem). Mesmo considerando o conjunto de críticas, ambigüidades e fragilidades que constituem os estudos que se amparam na metodologia de fontes orais 
(histórias de vida, entrevistas estruturadas ou semi-estruturadas, temáticas etc.) e procurando compreender os processos que envolvem este vasto e complexo campo que denominamos de formao de professores, Nóvoa registra sua crena no potencial inovador, já que "por aqui, pelas histórias de vida, pode passar a elaboração de novas propostas sobre formação de professores e sobre a profissão docente" (Ibidem: 25).

Mas, as carências de muitos pesquisadores em relação aos avanços nas metodologias de análises qualitativas de texto e nas teorizações desenvolvidas nas áreas da História, Antropologia, Teoria Literária e Semiótica, entre outras, ainda impedem o uma compreensão mais significativa dos conteúdos dos depoimentos e prejudicam, sensivelmente, uma colocação estratégica das fontes orais na construção interpretativa (PENNA, 2005).

Por fim, a inserção das fontes orais no presente trabalho, apesar das dificuldades apontadas, tem o objetivo de propor alguns caminhos para uma melhor utilização dessa estratégia de investigação, pois se acredita que o recurso das histórias de vida mostra-se eficiente em sua possibilidade de relacionar vivências de infância a vivências de docência. Dessa forma, percorremos e adaptamos experiências metodológicas de pesquisadores, para que, por intermédio de uma escuta atenta ao depoimento do professor, fosse percebida a dinâmica de uma memória sempre reatualizada, que recorta segmentos de vida para retraçar os passos de um passado norteador das ações presentes.

Histrias de vida: experimentos de anlise

Após uma primeira experiência conjunta de exercício metodológico com fontes orais (SILVA e PENNA, 2006), realizaram-se algumas modificações no tangente s questões culturais, no sentido de ampliar o escopo de possibilidades de compreensão das narrativas, articulando-as com os processos culturais de forma mais efetiva. Dessa forma, o papel da cultura adquiriu papel central e estratégico em nosso método, sendo importante compreendê-la de forma dinâmica e articulada a um campo de relações, pois:

A cultura tomada como referência para proceder a análise indica a possibilidade de revisão do próprio conceito de cultura. Deixar a imagem de um grande mosaico cultural no qual cada cultura tem seu espaço territorial definido e passar a interpretá-la como uma grande rede de relações que se mesclam e interagem, dividindo espaços 
comuns, pode contribuir nos trabalhos de investigação nesse campo (SILVA, 2006, p.29).

Denominou-se de quadro cultural essa rede de relações culturais que compõem as visões de mundo, partindo-se do pressuposto de que o espaço social é integrado pelos indivíduos que o percebem e o representam a partir dele, pois, de acordo com Stuart Hall (2003), o sujeito fala sempre a partir de uma posição histórica e cultural específica. Então, todo o sistema de representações, independente do que enfoca, poderá ser associado a um quadro cultural, por intermédio do qual se adota determinadas posições ao narrarmos algo.

Também se acredita não ser possível separar língua e exterioridade, pois não há sentido no lingüístico sem a exterioridade. Logo, um acontecimento histórico na visão de um indivíduo coloca em relação sua memória, uma realidade estruturada e uma atualidade, resultando em determinada materialidade discursiva. Instala-se, assim, um espaço para o acontecimento cujos objetos produzidos não estão presos a uma logicidade dada anteriormente, mas às condições históricas de produção de sentido. Essa historicidade impede o sentido de se sedimentar, porque há um real que insiste em ser considerado, sendo impossível de ser captado como um todo e do mesmo modo por todos os sujeitos do discurso. E é no ponto onde se dá a injunção de língua, sujeito e história que se constitui o lugar da opacidade da língua, do equívoco -esse é o espaço onde trabalha a interpretação.

Esses pressupostos indicam que as palavras e expressões mudam de sentido de acordo com as posições sustentadas por aqueles que as empregam, adquirindo seu significado em referência aos quadros culturais nos quais essas posições se inscrevem, descentralizando a noção de sujeito e centralizando a problemática nos sistemas de representação.

E é dessa forma, associando o narrador e suas representações ao contexto histórico-cultural na elaboração da história de vida, que se recorre a Paul Ricœur, o qual tem se apresentado, na tradição contemporânea, como um expoente nessa preocupação de se compreender o dito distanciando-se em parte da pretensão psicanalítica e concentrando-se na linguagem, porque o "mundo contado é o mundo do personagem e é contado pelo narrador" (1995: 147). 
Trabalhando a interpretação das narrativas dentro dos pressupostos apontados, levou-se em consideração que os discursos não se revelam de imediato, necessitando de uma metodologia de análise que desvende os nexos e relações estabelecidas entre experiência, memória e narrativa, e se buscando recursos que possibilitem compreender a entrevista para além de simples intuições. Procurou-se na prática a superação da ilusão de transparência (BARDIN, 1995, p.9).

Também estão presentes as noções sobre os mecanismos da memória negando a tendência de alguns pesquisadores de duvidar do entrevistado ou desmenti-lo na própria publicação (em certos casos, transcreve-se um trecho da entrevista e, logo a seguir, uma correção, em geral baseada em fontes escritas). Para tanto, recorremos obra de William Stern, o qual deixa claro que a função da lembrança é conservar o passado do indivíduo na forma que é mais apropriada a ele. O material indiferente é descartado, o desagradável, alterado, o pouco claro ou confuso simplifica-se por uma delimitação nítida e o trivial é elevado à hierarquia do insólito (apud PENNA, 2005).

Da hermenêutica, adotou-se a problemática de saber como é possível interpretar as descrições de sentido subjetivamente intencionais, tendo em conta o fato de passarem pela subjetividade do próprio intérprete. Tomou-se, como ponto de partida, a metodologia descrita e aplicada por pesquisadoras na área da Educação, no caso, o trabalho desenvolvido por Szymanski, Almeida e Prandini (2002), adaptando-a ou articulando-a aos já mencionados quadros culturais.

Aplicando a metodologia, primeiramente escolheu-se trechos das entrevistas que enunciavam o quadro cultural dos depoentes, a partir do qual construiriam suas formas de ver a educação em um sentido amplo, "tanto como a ação educativa elaborada e exercida por diferentes instituições orientadas para este fim, como o processo de socialização que se realiza ao longo de toda a vida, em casa, no trabalho e no lazer" (DEMARTINI, 2006, p.99). Após, recortou-se trechos dos relatos relacionados com a trajetória profissional, no sentido de destacar a visão de educação no sentido formal, com uma primeira descrição. Então, iniciou-se outra etapa da reflexão, realizando-se o trabalho intradescritivo, a partir de leituras e releituras do texto de referência. Elaborouse a síntese, no sentido interpretativo, a partir da seleção dos itens emergentes, 
referidos como unidades de significados, relacionando-a com o quadro cultural, na qual surgiu o oculto por intermédio do aparente.

No caso do presente trabalho, as entrevistas foram realizadas apenas uma vez, com cada uma das pessoas, impedindo um contato duradouro que permitisse o aprofundamento da relação, mas procurou-se adotar uma postura e sentimentos conectados reflexão de Dilthey (apud REIS, 2003), em que compreender o outro não é submetê-lo a alguma forma de controle externo, mas estabelecer com ele uma relação de confiança recíproca, respeitando as expressões da sua experiência vivida. Ao movimento de receio, desgosto e demais sentimentos de afastamento, cabe ao pesquisador a aproximação. Mas dificilmente o olhar do pesquisador poderá desvestir-se de alguns elementos pré-concebidos, admitindo-se, entretanto, o reconhecimento de sua própria subjetividade no movimento de análise.

\section{Interpretando as narrativas}

As entrevistas foram realizadas com R. R., casado, dois filhos, 46 anos, professor de História e com M. L., 57 anos, casada, professora de Letras. Para fins de operacionalização e fluência do texto, doravante denominaremos R. R. como entrevista $\mathrm{n}^{\mathrm{o}} 1$ e M. L. como entrevista ${ }^{\mathrm{o}} 2$.

Primeiro movimento:

Dialogando com os pesquisadores na área da formação e prática docente

Para orientar o diálogo com os pesquisadores na área da formação e prática docente, escolheu-se dois eixos temáticos presentes na formulação discursiva dos profissionais da educação entrevistados: o processo de formação e os saberes da prática docente.

Uma primeira direção, para se pensar sobre os processos de formação de professores, pode ser tomada a partir das experiências nos cursos de Licenciatura (também compreendida como Formação Inicial). Nesse contexto, os "estágios de ensino" se destacam como fundamentais, tanto no que diz respeito forma como são orientados, quanto variedade de pesquisas que enfatizam este momento da formação como objeto de estudo (MARCELO, 1998). 
Nunes (2001), apoiando-se nos estudos realizados por Fiorentini, et all, sintetiza significativamente quatro décadas de orientações das pesquisas. Enfatiza a autora que, na década de 60, os estudos centraram-se sobre os saberes que os professores possuíam de sua disciplina; já, na década de 70, os aspectos didático-metodológicos ganham acento nas preocupações dos pesquisadores. Em relação aos anos 80, a ênfase encontra-se na valorização da dimensão sócio-política e ideológica do fazer educativo; finalmente, os anos 90 "foram marcados pela busca de novos enfoques e paradigmas para a compreensão da prática docente e dos saberes dos professores" (NUNES, 2001: 30).

Observa-se, quanto aos professores entrevistados, que o encontro com "as teorias educativas" ganha relevância no espaço acadêmico, mesmo que sirvam, para sustentar a crítica do distanciamento entre as teorias elaboradas nesse universo e as práticas correntes no cotidiano escolar. Vejamos trecho da entrevista $\mathrm{n}^{0} 1$ :

A forma como a teoria é ensinada não ajuda muito. Para mim não ajudou. Eu acho que ela tem que ser mais didática, no sentido de que existe um mundo lá fora da academia, em que os estudantes de Pedagogia e de Letras e de qualquer outra ciência humana, seja história, matemática, química, física, em que a teoria, ela vai te servir para ser um farol, mas é o dia-a-dia do aluno [dá alguns exemplos].

$\mathrm{Ou}$ ainda na entrevista $\mathrm{n}^{\circ} 2$ :

Depois apareceram as teorias foi que eu fui dizer puxa vida, eu trabalhei com aquilo sem saber como estava trabalhando! E quando chegou no final do ano, "todos" estavam alfabetizados.

São atitudes paradoxais, pois, na medida em que os estudos na universidade vão avançando, espera-se que, a cada semestre concluído, tornemse mais claros e operantes os conceitos e apropriações teóricas para a ação docente, revelando que essas ações carregam concepções elaboradas pelo universo acadêmico, tanto no nível da graduação, quanto em cursos de pósgraduação. Mas, nas entrevistas, constata-se uma ênfase no ato individualizado de se fazer a articulação entre a prática e as teorias veiculadas na universidade. A assunção de que esta combinação é realizada pelo próprio docente (o entrevistado), distanciando-se do que e como foi realizado pelos professores no ensino superior, é assumida como autoria e esforço pessoal, em grande parte e, segundo os educadores entrevistados, só permitida pelas experiências vividas no passado e no ato mesmo de ensinar, produzindo um "contexto ideal" ou 
"pedaços" de uma história que o narrador reconstruiu (RICEUR, 1995). Portanto, já não se tem a história em si, no caso da trajetória e experiências de formação do educador, mas a maneira como (re) elaborou e (re) significou essas experiências. Nessa lógica de raciocínio, coloca-se como necessidade a relativização do quanto a teoria elaborada no universo acadêmico encontra-se realmente distante do fazer educativo e, igualmente, distante dos processos formativos como instigadora de novas/outras práticas e teorias da ação educativa.

Práticas e saberes da prática docente assumem preponderância nos discursos produzidos pelos dois educadores, privilegiando uma visão empirista dos processos de construção do saber, tanto no que se refere aos saberes inerentes atuação docente quanto aos saberes proporcionados pelas experiências do cotidiano. Pode-se perceber esta visão no seguinte trecho da entrevista $\mathrm{n}^{0}$ 1: " o seguinte: eu dou aula em cima da mesa, faço todo mundo subir em cima da mesa, dou aula no pátio, no corredor, quando o sol está batendo aqui, vamos ter aula aqui, em escada ... o que eu quero é que os meus alunos aprendam, não quero que eles decorem".

Acrescente-se outro trecho, agora da entrevista $n^{0}$ 2: "Lá na Unisinos comecei a estudar os teóricos, comecei a entender aquilo que os teóricos diziam, era o que eu fazia na pratica".

A própria noção de "improvisação" durante o ato educativo é, no mínimo, intrigante, levando em conta que, se por um lado, a improvisação pode ser considerada como um elemento a mais no processo educativo, por parte do educador, o que poderia se pensar como a capacidade de adequação, adaptação e mesmo criação, também pode ser vista como inexistência de planejamento, despreparo e ausência de habilidades e competências próprias da profissão docente.

O debate instaurado, atualmente, entre as relações, correlações e pertinências dos saberes oficiais e saberes práticos revelados nas ações educativas de profissionais da educação, continua sendo instigante para a construção das possibilidades de análise do quê e como realmente se dá o processo de ensinar e aprender e de quais são os conhecimentos que o professor lança mão neste processo. Para Sandra Azzi, “O saber pedagógico é o saber que o professor constrói no cotidiano de seu trabalho e que fundamenta sua ação 
docente, ou seja, é o saber que possibilita ao professor interagir com seus alunos, na sala de aula, no contexto da escola onde atua" (2003: 43). Assim sendo, o professor se ancora nos conhecimentos científicos apropriados durante sua formação acadêmica e, dinamicamente, os (re)elabora no ato mesmo de ensinar.

Outro aspecto que se revela neste processo de pensar esses saberes é a própria noção do processo sobre a produção desse conhecimento na prática. Possivelmente, seja este um dos aspectos que diferencia o saber pedagógico do conhecimento científico. A clareza do processo de como se produz, o que em grande medida os professores acabam não tendo ou não podendo, pelas exigências do fazer educativo cotidiano e toda a sua complexidade, lançar um olhar reflexivo sobre este fazer. Por outro lado, permanece a possibilidade de que os educadores possam estar realizando um ato reflexivo sobre seus fazeres educativos, entretanto, a própria academia e seus intelectuais ainda não conseguiram construir dispositivos metodológicos e conceituais capazes de permitir a reflexão desse objeto de estudo tão pouco explorado.

Segundo movimento:

elaborando uma síntese entre a produção do saber docente e os quadros culturais

De acordo com Augras (1997), trabalhar a riqueza de uma narrativa apenas é possível pela análise da linguagem utilizada pelo entrevistado. Nossa escuta é o registro dessa fala, não esquecendo que a fonte oral não fornece dados, ela nos oferece um discurso. Quando se trata de uma pessoa viva, que interage com outra ao longo da entrevista, é essa dinâmica que se torna a fonte de informação. Nesse contexto de pesquisa, a única técnica na qual podemos nos apoiar é a análise do seu discurso, pois os fatos de que dispomos são dados de linguagem.

Neste texto, buscou-se contribuir para o complexo processo de análise de fontes orais, que envolve intersubjetividades, memória e narrativa, enfocando a problemática de compreender como os professores incorporam os elementos de sua vida pregressa, principalmente experiências de aprendizado na infância, no atual exercício da docência. Para tanto, o fato de a metodologia inserir a fala dos professores, sobre o exercício de sua profissão, na moldura de um quadro cultural formado ao longo de sua vida e fortemente alicerçado nos valores 
ensinados na infância, permitiu compreender o aparente paradoxo de profissionais que vivem e trabalham com atividades baseadas na reflexão intelectual professarem certo anti-intelectualismo, valorizando práticas e aprendizagens supostamente dissociadas da teoria. Estes movimentos podem ser percebidos nos seguintes trechos da entrevista $n^{\circ}$ 1: "Em 1986 fui fazer Administração na Unisinos e aí eu fiz uma burrada, porque eu descobri que eu sabia mais que os professores, ou pelo menos o que eles ensinavam em sala de aula, eu já sabia de cor e salteado pela minha carreira profissional e eu desisti”.

$\mathrm{E}$, de forma mais evidente, na entrevista $\mathrm{n}^{\circ} 2$ : “

\begin{abstract}
Uma experiência riquíssima que eu tive, eu e meus irmãos, eu não lembro em que série a gente estava, mas eu me lembro bem que quando nós fomos buscar água no poço, pra lavar a escola, tinha uns bichinhos dentro da água e nós pensamos ah, é peixe, vamos levar os peixes pra casa. Pegamos uma caneca e levamos aqueles bichos pra casa dentro da água. No caminho era tapas pra cá, pra lá, um queria pegar e tal. Chegando em casa mostramos pro nono, ele olhou ah... Muito bem, vamos ver o que vai dar isso. Eu vou botar um coxo de cimento que era pro terneiro beber; ali vai criar os peixes de vocês. Mas ele dizia de tal jeito e fez aquilo tão direitinho, que não xingou nem nada. Nós esperamos e daí a pouco não era peixe, era girino, virou sapo, mas ele sabia, ele sabia, por isso que ele não mandou nós botar, colocarmos fora, por que ele sabia que aquilo ali ia virar sapo. $\mathrm{E}$ vocês vêm, ele não tinha instrução, ele sabia ler e escrever porque tinha sido "autodidata" né, mas ele deixava nós aprendermos, com as nossas experiências e até com os nossos erros.
\end{abstract}

Bhabha (1998) analisa que, no processo de tradução, elaboramos uma narrativa que pode reunir elementos antitéticos na busca de uma discursividade que pareça coerente a nós e aos outros a quem apresentamos nossa fala. Ocorre algo que podemos associar a processos simbólicos de tensão, negociação e tradução, em uma linha que introduz a reinvenção criativa da existência. Esses elementos podem ser percebidos nas representações da prática pedagógica dos professores entrevistados, surgindo um discurso em que os elementos presentes misturam e ultrapassam tanto a experiência de vida nos estágios iniciais da infância e pré-adolescência, como a experiência relativa à prática de ensino.

É natural que assim ocorra, pois, conforme anotado por Souza (2003: 65), a percepção da relação entre educação e cultura(s) não pode mais se limitar ao âmbito dos conteúdos culturais, ou do currículo escolar, "configurando-se em complexa teia de interpretações tecidas entre os pontos de vista dos sujeitos do processo educacional”.

Assim, o discurso resultante dos entrevistados, ao relatar sua prática pedagógica, demonstra que a cultura escolar (currículo formal, conteúdos etc.) 
efetiva-se sob a influência tanto do quadro cultural formado nos cotidianos privados, como dos saberes adquiridos na formação superior. O resultado é um campo complexo traduzido por uma costura peculiar entre o empírico (as vivências extra-academia) e o teórico (conceitos e formulações de pensadores acadêmicos), em que "os processos simbólicos de tradução tornam possível a articulação de elementos antagônicos ou contraditórios" (Ibidem: 78).

Percebeu-se que o quadro cultural dos professores entrevistados demonstrou que ambos carregavam valores tradicionais em relação à família e seu papel na educação, colocando o formato da sociedade atual (individualismos, papéis pouco precisos da família, ausências) como responsável pelos conflitos entre professores e estudantes. Na entrevista $\mathrm{n}^{0} 1$, evidencia-se esta noção:

\begin{abstract}
A nossa sociedade capitalista, hoje em dia, que é a melhor que tem, não adianta, ela nos impulsiona para este lado. Ela vai nos empurrando para que a gente seja cada vez mais individualista, cada vez menos participativos, cada vez menos conversadores, mais visual. Nós vivemos numa sociedade com mais estímulos visuais que estímulos de papo.
\end{abstract}

A noção de perda de valores familiares e o contato com uma suposta "vida real" é expressa na entrevista $\mathrm{n}^{0} 2$ :

Eu agradeço muito, muito aos meus antepassados, aos meus nonos, aos meus avôs, aos meus tios, meus pais, por todos, a sabedoria que eles nos passaram, tanto a mim, quanto aos meus filhos que também tiveram a graça de conviver com os avôs e bisavôs. Então, as experiências significativas que eles tiveram foi da tenra idade, foi deles.

E, quando os professores entrevistados demonstraram a valorização da experiência prática, adquirida durante a infância, como fator orientador de sua atuação docente, citaram alguns teóricos em suas entrevistas, como Freire e Piaget, no sentido de que os mesmos também valorizariam o caráter prático do saber, quase antagonizando com a teoria, relegando-a a um caráter de "mal necessário".

Paulo Freire foi citado como reforço a essa idéia, não tendo sido percebido que, para ele, a teoria não se torna verbalismo nem a prática, automatismo, se utilizadas, dentro dos pressupostos em que a teoria implica uma inserção na realidade, um contato analítico com o existente, para comprová-lo, para vivê-lo e vivê-lo plenamente, praticamente. Efetivamente, Paulo Freire (1999) rebate a afirmação de que o pecado de nossa educação é ser teórica, dizendo que nossa 
educação não é teórica porque lhe falta esse gosto da comprovação, da invenção, da pesquisa. Ela é verbosa no sentido que lhe atribuímos quando a teoria se pretende auto-suficiente, pois é no relacionamento teoria-prática que temos o caráter dinâmico da transformação tanto de uma como de outra.

Por fim, as reflexões aqui brevemente mencionadas buscaram auxiliar na construção de uma metodologia de análise de fontes orais que desvendasse os nexos existentes entre vida privada e vida profissional, os laços entre cultura do cotidiano e cultura escolar, bem como as relações estabelecidas pelos atores sociais entre o seu passado e a experiência do presente. Resta-nos concluir que nosso estudo, bem mais do que criticar ou tentar estabelecer novas luzes sobre as questões da metodologia com fontes orais e a formação de professores, demonstrou a necessidade de reflexões sobre a formação do professor que realizem a associação dos saberes da experiência que são mobilizados na prática, pois, transformados, eles passam a integrar a identidade do professor, influenciando efetivamente nas decisões pedagógicas.

\section{Bibliografia}

AUGRAS, Monique. História oral e subjetividade. IN: SIMSON, Olga Rodrigues de Moraes Von (org.). Os desafios contemporâneos da História Oral. Campinas: Área de Publicações CMU/Unicamp, 1997.

AZZI, Sandra. Trabalho docente: autonomia didática e construção do saber pedagógico. IN: PIMENTA, Selma Garrido (org.). Saberes pedagógicos e atividade docente. $3^{\mathrm{a}}$. ed. Rio de Janeiro: Cortez, 2002, pp. 35-60.

BARDIN, Laurence. Análise de conteúdo. Lisboa: Edições 70, 1995.

BHABHA, Homi K. O local da cultura. Belo Horizonte: UFMG, 1998. Tradução Myriam Ávila, Eliana Lourenço de Lima Reis, Gláucia Renate Gonçalves.

BUENO, Belmira Oliveira et. all. Histórias de vida e autobiografias na formação de professores e profissão docente (Brasil, 1998-2003). Educação e Pesquisa, São Paulo, v. 32, n. 2, mai/ago de 2006, pp. 385-410.

DORNELES, Elizabeth Fontoura. O discurso do MST: um acontecimento na estrutura agrária brasileira. IN: INDURSKY, Freda e FERREIRA, M. Cristina (org.). Os múltiplos territórios da análise de discurso. Porto Alegre. Ed. Sagra Luzzato, 1999, pp. 149-186.

DEMARTINI, Zélia; TENCA, Álvaro; e TENCA, Sueli. Velhos mestres das novas escolas: um estudo das memórias dos professores da $1^{a}$ República. Relatório de Pesquisa. São Paulo, INPE/CERU, 1985.

DEMARTINI, Zeila. Memória e Educação. Caminho para a reflexão e a diversidade. IN: WORCMAN, Karen e PEREIRA, Jesus (org.) História falada: 
memória, rede e mudança social. São Paulo: SESC SP: Museu da Pessoa: imprensa oficial do Estado de São Paulo, 2006.

FREIRE, Paulo. Educação como prática da liberdade. Rio de Janeiro: Paz e Terra, 1999.

GRISA, Jairo Ângelo. Os sentidos culturais da escuta: Rádio e Audiência Popular. Dissertação de Mestrado. Porto Alegre: Universidade Federal do Rio Grande do Sul, Faculdade de Biblioteconomia e Comunicação, Programa de Pós-Graduação em Comunicação e Informação, 1999.

HALL, Stuart. Estudos culturais e seu legado histórico. IN: SOVIK, Liv (org.). Da diáspora. Identidades e mediações culturais. Belo Horizonte: Editora UFMG, 2003, pp. 199-218. Tradução Adelaine La Guardiã Resende (et. al).

MARCELO, Carlos. Pesquisa e formação de professores. O conhecimento sobre o ensinar e o aprender. Revista Brasileira de Educação, set/out/nov/dez, n. o9, 1998, pp. 51-75.

NÓVOA, António. Os professores e as histórias de suas vidas. IN: (org.). Vidas de Professores. ${ }^{\mathrm{a}}$. ed. Porto: Porto Editora, 2000, pp. 11-30 (Coleção Ciências da Educação)

NUNES. Célia Maria Fernandes. Saberes Docentes e Formação de Professores: um breve panorama da pesquisa. Educação \& Sociedade, ano XXII, no 74 , abril de 2001. Disponível em <http://www.scielo.br/pdf/es/v22n74/ao3v2274.pdf>. Acessado em 15/05/2006.

PENNA, Rejane. Fontes orais e historiografia - avanços e perspectivas. Porto Alegre: Edipucrs, 2005.

PINTO, Neuza Bertoni. Saberes docentes e processos formativos. Revista Diálogo Educacional, v.2, n.3, jan-jun de 2001, pp. 43-57.

REIS, José Carlos. Dilthey: para uma revolução moral e intelectual. IN: LOPES, Marcos Antônio (org.) Grandes nomes da História Intelectual. São Paulo: Contexto, 2003.

RICEUR, Paul. Tempo e narrativa. Tomo II. São Paulo: Papirus, 1995.

ROUSSO, Henry. A memória não é mais o que era. IN: AMADO, Janaína e FERREIRA, Marieta de Morais (orgs.). Usos e abusos da História Oral. Rio de Janeiro: Editora da Fundação Getúlio Vargas, 1996, pp. 93-101.

SILVA, Gilberto Ferreira; PENNA, Rejane. Discursos e trajetórias de estudantes brasileiros afro-descendentes no ensino superior. Revista Internacional Interdisciplinar INTERthesis, v.3, n.1, Florianópolis, jan/jun de 2006. Disponível em $<$ http://www.interthesis.cfh.ufsc.br/interthesis5/artigos/penna_silva_interthe sis5.pdf $>$. Acessado em 17/05/2007.

SZYMANSKI, Heloisa; ALMEIDA, Laurinda; PRANDINI, Regina. Perspectivas para análise de entrevistas. IN: SZYMANSKI, Heloisa (org.). A entrevista na pesquisa em educação: a prática reflexiva. Brasília: Plano Editora, 2002, pp. 62-86.

SOUZA, Maria Izabel Porto de; FLEURI, Reinaldo Matias. Entre limites e limiares de culturas: educação na perspectiva intercultural. IN: FLEURI, Reinaldo Matias (org.). Educação intercultural. Mediações necessárias. Rio de Janeiro: DP\&A, 2003, pp. 53-84. 
Rejane Silva Penna e Gilberto Ferreira da Silva

Experiências pessoais e suas implicações nas práticas de ensino

SILVA, Gilberto Ferreira da, (2006). Da embriaguez de um conceito, procurando a sustentabilidade das diferenças e das identidades. IN: PENNA, Rejane; TOALDO, Ana Maria; e SABEDOT, Sydney. Conhecimento, sustentabilidade e desenvolvimento regional. Canoas: Unilasalle, 2006, pp. 2332.

Colaboração recebida em 19/03/2009 e aprovada em 18/06/2009. 